\title{
LA SUBJETIVIDAD CONTEMPORÁNEA INTERPRETADA DIACRÓNICAMENTE A PARTIR DE G.B. VICO
}

\author{
CONTEMPORARY SUBJECTIVITY INTERPRETED \\ DIACHRONICALLY FROM G.B. VICO.
}

Alfonso GARCÍA MARQUÉS
Universidad de Murcia
$\underline{\text { marques } @ \text { um.es }}$

Resumen:El presente artículo es una interpretación de la subjetividad contemporánea a partir de la teoría de Vico sobre el origen y principios de todo lo humano. Se adopta un enfoque diacrónico para dar razón de la pluralidad de subjetividades que se han sucedido a lo largo de la historia y se muestra en qué concuerda y discrepa la subjetividad actual respecto a otras subjetividades del pasado.

Palabras clave: Subjetividad, temporalidad, ciclo histórico, Vico, diacronía.

Abstract: This paper is an interpretation of contemporary subjectivity based on Vico's theory about the origin and principles of the human. The point of view adopted is diachronic in order to give reason for the plurality of subjectivities that have occurred throughout history and it shows how actual subjectivity agrees and disagrees with other subjectivities from the past.

Keywords: subjectivity, temporality, historical cycle, Vico, diachrony. 


\section{1}

\section{.Presentación del problema}

El estudio de la subjetividad puede enfocarse desde muchos puntos de vista: ontológico o existencial, diacrónico o sincrónico, individual o colectivo, etc. El tema propuesto por la revista Tropelias para el presente volumen, la subjetividad contemporánea, avala un enfoque diacrónico, pues bajo el término contemporáneo subyace la idea de que ha habido otras subjetividades distintas de la actual, aunque centra el foco en la interpretación de nuestra subjetividad.

¿Qué caracteriza el enfoque actual del estudio de la subjetividad, frente a enfoques de otras épocas? Me parece que hoy día ya no se atiende principalmente a la perspectiva metafísica, sino a la existencial. Preguntar por la identidad de un yo, de una persona concreta, de una subjetividad, no es hacer una pregunta ontológica, sino existencial, narrativa. Ya Buber, como es bien sabido, desplazó la pregunta de qué es el hombre a la cuestión de quién soy yo. Por eso mismo, el tema de la subjetividad ya no se enmarca preferentemente en el ámbito cognitivo, sino en el de la de acción: al interrogarnos por un $y o$, no nos preguntamos por una teoría del conocimiento, sino por la praxis humana. Y por último, podríamos añadir que hoy día hay un conjunto de tendencias posmodernas que conducen la desconstrucción del sujeto o, en general, a su disolución.

Dejando momentáneamente de lado la cuestión de la disolución del sujeto, si nos atenemos a los enfoques actuales mencionados -existencial, práctico, identitario, individual-, puede parecer que la subjetividad contemporánea es algo único: el sujeto moderno nacido en el XVIII es la auténtica subjetividad, frente al cual las otras formas de autoconciencia apenas merecen ser llamadas subjetividad. Podemos considerar, por ejemplo, que la sustantivación de yo, del pronombre de primera persona, o sea, hablar de el yo, es un fenómeno muy reciente que no aparece en la literatura antigua o medieval.

Ahora bien, ¿podemos dar como bueno que la conciencia de la individualidad, el valor de la propia subjetividad, no ha aparecido hasta tiempos recientes? Ateniéndome a una perspectiva diacrónica, voy a intentar mostrar que a lo largo de la historia de Europa ha habido diversas formas de subjetividad, algunas tan plenas y autoconscientes como la nuestra. Como la nuestra, digo, en su mejor momento, pues no podemos olvidar los procesos de disolución a que la subjetividad contemporánea está siendo sometida.

\section{La multiplicidad diacrónica de las subjetividades en G.B. Vico}

Una de las tesis centrales legadas por la filosofía antigua sobre el sujeto humano, que permanecería inalterada hasta el siglo XVIII, es la idea de que el hombre posee una mente o intelecto, igual para todos y cada uno de nosotros, y eso es lo que nos caracteriza esencialmente. El hombre es el zôon logikón, el animal rationale: todo ser humano conoce y piensa según los mismos proceso lógico-cognitivos, de ahí que se pueda construir una lógica científica de validez universal. Esta homogeneidad de la racionalidad humana encuentra, a veces, versiones radicales como la unicidad del 


\section{Tropelias. Revista de Teoría de la Literatura y Literatura Comparada, 31 (2019) La subjetividad contemporánea interpretada diacrónicamente a partir de G.B. Vico \\ intelecto humano de algunos averroístas o como la res cogitans cartesiana, totalmente ahistórica y} autónoma respecto al cuerpo ${ }^{1}$.

\section{a) Las modificaciones de la mente}

En el XVIII aparece una novedad radical que va a transformar el panorama descrito: la concepción viquiana de la mente y, en concreto, la introducción del concepto de modificación de la mente. Con Giambattista Vico surge la idea de que la subjetividad humana no es un sujeto autoconsciente ahistórico, sino que ha de ser concebido de modo evolutivo y narrativo. Con otras palabras, mente ya no se conjuga en singular, sino en plural: hay una diversidad de mentes o posibilidad de pensar y actuar, que, al menos aparentemente, rompen con la presunta homogeneidad de la razón humana. Y además, esa pluralidad de mentes es diacrónica: a través del tiempo se han dado y darán diversos tipos de sujetos -o de subjetividades-, a veces irreductibles entre sí.

Para explicitar esa tesis, Vico describe el proceso de la humanidad como una transición desde el vagar ferino hasta la creación de sociedades complejas: «El orden de las cosas humanas procedió así: primero fueron las selvas, luego las chozas, después los pueblos, posteriormente las ciudades y finalmente las academias» (SN 239) ${ }^{2}$. Este proceso se estructura básicamente según la teoría de los ritmos ternarios de la humanidad, lo cual implica la temporalización de todo lo humano: las lenguas, los caracteres, las costumbres, el derecho, la ciencia e incluso la misma naturaleza humana: «Hubo tres edades: la edad de los dioses, la edad de los héroes y la edad de los hombres» (SN 173). Esta procesualidad de lo humano se ve incrementada por la introducción de los corsi e ricorsi: toda la humanidad está en un continuo proceso histórico de nacimiento, crecimiento, decadencia y vuelta a empezar, aunque, como es lógico, un nuevo ciclo nunca es idéntico a cualquiera de los anteriores.

Esta visión de Vico parece dar lugar a una relativización de cada época histórica, que ha de ser entendida desde ella misma, sin que pueda ser juzgada desde otra posterior o anterior. Esto tendría la ventaja de permitir la revalorización de elementos humanos, tales como la sensibilidad o la fantasía o la creación artística, frente a los elementos racionales, tales como la filosofía o la ciencia. Dicho de otro modo, tan humana sería una época imaginativo-creadora como una filosófico-científica. Y además, atendiendo a que «la naturaleza de las cosas no es más que nacimiento de ellas en ciertos tiempos y con ciertas propiedades» (SN 147), parece que habría que sostener que la verdadera naturaleza humana es la imaginativo-creadora y no la racional-científica.

Para entender toda esta procesualidad, Vico busca las condiciones que posibilitan el nacimiento y el devenir del mundo civil. En un célebre pasaje de la Scienza nuova del 1744, Vico afirma que las ha encontrado:

\footnotetext{
${ }^{1}$ Este cartesianismo todavía se puede rastrear en los planteamientos filosóficos y científicos que hablan de las relaciones mente-cerebro o mente-cuerpo, tema muy presente en la filosofía analítica o en las actuales neurociencias. Sin embargo, este enfoque abandona en buena medida el problema de la subjetividad consciente, para limitarse a la cuestión puramente cognitiva, estrechamente emparentada con el conocimiento animal o incluso, hoy día, con el vegetal (inteligencia mínima) (Calvo, 2016: 1323-1343).

${ }^{2}$ Como es canónico, utilizo SN con los números de la edición Nicolini, para citar a Vico, Principi di Scienza nuova d'intorno alla natura comune delle nazioni.
} 


\begin{abstract}
En tal densa noche de tinieblas, que cubrían la primera antigüedad, alejadísima de nosotros, aparece la luz eterna, sin ocaso, de esta verdad, que no puede ponerse en duda bajo ningún concepto: que este mundo civil ha sido ciertamente hecho por los hombres, de ahí que se puedan, porque se deben, encontrar los principios dentro de las modificaciones de muestra misma mente humana (SN 331).
\end{abstract}

En este texto capital, está presente la doctrina viquiana del verum factum: nosotros podemos conocer el mundo civil, puesto que lo hacemos; dicho de otro modo: ya que nosotros lo hemos hecho, en nuestra mente, en nuestra subjetividad, se hallan los principios de los cuales este mundo ha nacido ${ }^{3}$. Ahora bien, en dicho texto no sólo está operante el verum factum, sino que en él Vico introduce el concepto de modificación de la mente, afirmando que los principios de nuestra praxis y del mundo civil están no en la mente sin más, sino «dentro de las modificaciones de nuestra misma mente humana». Vico subraya explícitamente que el descubrimiento de los diversos tipos de mente -las modificaciones-, o sea, los diversos tipos de subjetividad y cómo funcionan «es la clave maestra de esta Ciencia» (SN 34); y que las dificultades que ha tenido para encontrarlas «nos han costado la búsqueda obstinada de casi toda nuestra vida literaria» (SN 34, 338).

Si no yerro, este hallazgo de Vico representa una novedad radical en la historia del pensamiento: por primera vez, en toda la historia de la filosofía, se concibe la idea de una mente humana no como algo estático, que siempre conoce en modo intelectivo, sino como algo que se modifica intrínsecamente, originando tipos de conocimiento radicalmente distintos: uno imaginativo y otro racional. En pocas palabras: las condiciones de posibilidad de la actividad de la mente varían intrínsecamente según un despliegue temporal. Lo cual implica que las condiciones de comprensión de la subjetividad humana varía temporalmente, tanto para la comprensión de sí misma, como del mundo natural, como del mundo civil o humano que ella misma crea a partir de sí misma.

\title{
b) Los tipos de subjetividad
}

En la elaboración de la teoría de las modificaciones, Vico atiende tanto a la unidad entre cuerpo y mente, como a la pluralidad de niveles cognitivos humanos, según los cuales los modos de conocer del sujeto humano van de lo sensible a lo inteligible. Es decir, todo conocimiento humano ha de empezar por los sentidos y de ahí proceder a la mente; así, tanto en los niños como en los hombres primitivos, el conocimiento es principalmente sensitivo, mientras que, en los hombres de la sociedad desarrollada, es intelectivo: «Los hombres primero sienten sin advertir, después advierten con ánimo perturbado y conmovido, finalmente reflexionan con mente pura» (SN 218; cfr. Jacobelli, 1968: 4445).

A partir del texto anterior, y de otros muchos pasajes paralelos, podría pensarse que son tres las modificaciones de la mente o tipos de subjetividad, según el predominio del sentido, de la fantasía o

\footnotetext{
${ }^{3}$ Aunque la vigencia del verum factum en la obra final de Vico ha sido objeto de discusión, hoy día podemos considerar aceptada la tesis de la continuidad de la obra viquiana (Otto, 1977: 16). Es más, pienso que toda la obra de Vico está permeada por ese principio, que, en definitiva, es la estructura operativa de toda mente, sea divina o humana. Incluso las distintas versiones que Vico ofrece de su pensamiento dependen del grado de madurez que el verum factum iba alcanzando en su mente (García Marqués, 2016-2017: 143-162; Zúnica, 1998: 179).
} 


\section{Tropelías. Revista de Teoría de la Literatura y Literatura Comparada, 31 (2019)

de la razón, como diversos intérpretes de Vico han señalado: «La serie de las modificaciones es expresada, mejor que por cualquier otra, por la sucesión de sentido, fantasía y razón» (Severino, 1981: 71). Sin embargo, en mi opinión, habría que decir que son solamente dos las modificaciones fundamentales: la mente poética (creadora) y la mente reflexiva, porque tanto los sentidos como la fantasía pertenecen al plano de lo sensitivo-particular distinto del plano universal-racional. Eso da lugar a la dialéctica fundamental de la Scienza nuova entre fantasía y razón, que en último extremo responde -lo cual es decisivo- a la estructura binaria del verum factum: momento creador y momento reflexivo (García Marqués, 1995: 17-34, 110-112). En consecuencia, para Vico hay solamente dos formas de saber: la sapienza poetica e la sapienza riposta. La primera se hace según los universales fantásticos (géneros imaginativos o caracteres poéticos) ( $\mathrm{SN} 34$ ), y la segunda, mediante ideas, que es lo propio de la perfección de la humanidad (SN 338, 1045). En suma, tenemos una subjetividad imaginativa y una subjetividad racional, una sabiduría poética y otra reflexiva, respectivamente.

Teniendo en cuenta el desarrollo necesario de la razón humana - de una mente poética a una mente reflexiva-, es claro que las modificaciones no son simultáneas, sino sucesivas: el proceso de humanización comienza por las creaciones de la mente poética y pasa, más tarde, a culminación con las grandes obras de la humanidad reflexiva (las artes, las ciencias, la filosofía) $(1 \mathrm{SN} 2,10)^{4}$.

Esto significa, por un lado, que la humanidad comenzó a pensar en modo humano según la mente poética y, por tanto, la sabiduría que poseyó fue necesariamente poética, y luego, a partir de tal conocimiento y sus consecuentes actividades, se fueron formando los saberes reflexivos. Por tanto, los saberes poéticos precedieron a los reflexivos y fueron la condición histórica de su nacimiento. Por otro lado, teniendo en cuenta que el estado perfecto de la humanidad es el posterior, o sea, cuando la razón está totalmente desarrollada, hemos de concluir que las ciencias y las actividades perfectas serán las reflexivas, no las poéticas, que no pasaron de ser un esbozo, un tanteo respecto a las posteriores elaboraciones. En definitiva, la primera subjetividad concibió la sabiduría poética y la segunda subjetividad, a partir de la sabiduría espontánea, engendró la sabiduría reflexiva:

A partir de la sapienza volgare, que es la ciencia de las cosas divinas de la religión y humanas de las leyes, nació la sapienza riposta de las divinas cosas metafísicas, de las verdades matemáticas y de los principios de la física y de las cosas humanas que se tratan en la filosofía moral, económica y civil (1SN 247).

Y así, los primeros pueblos, que fueron los niños del género humano, fundaron primero el mundo de las artes, después los filósofos, que vinieron mucho más tarde y, en consecuencia, son los viejos de las naciones, fundaron el mundo de las ciencias, con lo que de hecho se completó la humanidad (SN 498).

\section{Los dos corsi de Europa}

Atendiendo a la propuesta viquiana, en cuanto al tema que nos ocupa, podríamos sostener que, efectivamente, a lo largo del tiempo van apareciendo diversos tipos de subjetividades, en los que se va alcanzando un mayor grado de autoconciencia, y a partir de cada tipo de subjetividad se construye la

\footnotetext{
${ }^{4}$ Como es habitual, utilizo 1SN con los números de la edición Nicolini, para citar la Scienza nuova de 1725.
} 
propia identidad, praxis y mundo civil. Hagamos, pues, alguna aclaración histórica sobre esos diversos tipos de subjetividad.

Vico usa su teoría de las modificaciones de la mente y de los corsi y ricorsi para entender la historia de las naciones, o sea, de cada una de las unidades sociedades humanas en todos sus aspectos. Sin embargo, el mismo Vico tiene presente de modo paradigmático el corso de Roma, pues justamente la decadencia de Roma y su desaparición es lo mismo que el hundimiento del mundo antiguo. Desde esta perspectiva viquiana, podemos considerar que la división de nuestra historia en las cuatro edades (antigua, media, moderna y contemporánea) aporta suficiente comprensión ni claridad. Europa ha tenido dos corsi viquianos. Hablando en fechas simbólicas, el primero va desde el 753 a.C., con la fundación de Roma y composición de la Ilíada y la Odisea, hasta el 754 p.C., con la subida al poder de los carolingios, la ruptura entre Roma y Constantinopla, y la expansión del islam. A partir de entonces comienza el segundo corso de Europa, el nuestro: se inicia la formación de los reinos medievales, que darán lugar a las naciones modernas europeas que somos nosotros como unidades históricas; se formarán las entidades más características de nuestro mundo: la universidades medievales, que darán lugar a las modernas; y así en todos los órdenes.

Esto significa que nuestra subjetividad ha ido pasando por las diversas fases de dos ciclos ya casi completos; es decir, hemos tenidos dos sujetos poéticos y dos sujetos reflexivos. El primer corso ya ha sido recorrido completamente, y se agotó cuando su periodo de decadencia -que luego consideraremos- tocó fondo; el nuestro, por el contrario, está aún siendo recorrido y habría que evaluar en qué momento se halla.

Atendamos al mundo antiguo, al primer ciclo viquiano. Ahí encontramos no sólo una primera subjetividad creadora, que, de modo espontáneo, sin teorizar, fue capaz de unirse en comunidades cada vez mayores hasta crear las poleis griegas y las latinas, y de modo especial, Roma. Y esa civilización recorrió todas las etapas hasta conseguir logros extraordinarios en todos los ámbitos, incluidos el de la subjetividad, que es de donde nacieron esos logros. Por eso, si atendemos a la filosofía, literatura y arte de la Antigüedad es fácil comprobar que la conciencia de la propia subjetividad y personalidad alcanzó un pleno desarrollo, que emerge con fuerza en el estoicismo griego, y alcanza su cumbre en el estoicismo romano con Cicerón-Cartas familiares y Cartas a Ático-, con Séneca-Cartas a Lucilioo con Marco Aurelio-Meditaciones-. En el arte podemos encontrar una expresión clara de esa subjetividad madura en el retrato romano: no sólo tenemos los de los emperadores, donde podemos ver el carácter de cada uno plasmado en mármol, sino también en los retratos de El Fayum (del siglo I a.C. al III p.C), obras maestras que reflejan la psicología humana individual.

La conciencia antigua, en su momento de plenitud, concebía al sujeto como una unidad autoconsciente, que a través de la adquisición de las ciencias, las artes y las virtudes era capaz de autoconstruirse y desplegar su actividad en el mundo natural y humano. El centro del sujeto humano era su razón, que se cumple en dos tipos de actividades, las teóricas y las prácticas, de tal modo que lo humano se identifica con lo racional: hasta donde llega la razón llega lo propiamente humano. Podemos leer esta tesis en Aristóteles, quien ha sostenido que «el hombre es su intelecto; o, al menos, 


\section{Tropelías. Revista de Teoría de la Literatura y Literatura Comparada, 31 (2019) La subjetividad contemporánea interpretada diacrónicamente a partir de G.B. Vico}

principalmente» (Ethica nicomachea, IX, 8, 1169 a 2-3) y Agustín de Hipona: «Considero que en la mente se halla el sumo bien de los hombres» (Contra academicos III, 12, 27). La elaboración cumbre del mundo antiguo fue la idea de humanitas, como perfección del propio sujeto en sí, que separa lo plenamente humano de lo parcialmente humano: «Aunque todos se llamen hombres, solamente lo son aquellos que han adquirido una perfección adecuada por medio de las disciplinas propiamente humanas», (Cicerón, De re publica, I, 17, 28). De este modo, el cultivo de la subjetividad en sí misma, a través de las disciplinas y de todos los demás aspectos del ser humano, en la medida en que caen bajo la razón, constituye la concepción del hombre, de la subjetividad y del ideal de vida humana. Podemos ver totalmente explicitado esta idea de sujeto humano en las Confessiones de Agustín de Hipona, donde la narración de los conflictos de facultades tiene un puesto central, y donde la resolución de tales conflictos sólo puede darse en el hombre interior.

En consecuencia, podríamos decir que, en la Antigüedad, hay un sujeto humano, consciente de sí, cuya dimensión principal -no única- es el pensamiento, el conocimiento de sí mismo y de la realidad, capaz de dar razón de la realidad (teoría) y guiar la totalidad de la vida práctica (praxis). Se trata, pues, de una razón plena la que todos coincidimos igualmente, que es capaz de universalidad, o sea, de establecer conocimientos teóricos y prácticos, válidos para todo ser pensante. Validez que procede de su conformación con la physis -verdad teórica- o con la natura humana -la verdad práctica-. En definitiva, se pueden construir dos cuerpos de conocimientos: la episteme y el ius naturale gentium, cuya posesión y práctica hace que seamos sujetos humanos con total autoconciencia que viven humanamente.

Como es bien sabido, ese mundo entró en decadencia no tanto por presiones externas sino por una exaltación individualista de la propia subjetividad. No hay que olvidar que Roma liquidó su esplendor con la anarquía militar del siglo III, que duró casi 50 años, un fenómeno puramente interno, que tiene su raíz en los deseos individualistas de los ciudadanos frente a su propia sociedad. A partir de entonces ya no tenemos el Principado, sino el Dominado y comienza la Antigüedad tardía.

El segundo ciclo europeo, el nuestro, comienza con las formas de conciencia donde los dioses y la magia se mezclan con los hombres. Una época donde la reflexión, la crítica las ciencias y la filosofía están del todo ausentes, pero en cambio comienzan los procesos colectivos que darán lugar a nuestras naciones modernas y a nuestras estructuras sociales. Por ejemplo, si nos preguntamos dónde surgió el primer parlamento, dónde se dio el primer concejo..., siempre acudimos a esa primera etapa de nuestra humanidad. Pero esa inicial etapa no es lo que mal llamamos Edad Media, sino los tres siglos (7501050) de nuestra infancia, antes de empezar lo que llamamos el despertar de Europa, donde las ciencias, el derecho, la medicina, la filosofía comienzan su nueva existencia y anuncian la creación de los centros de saber teórico y práctico, las universidades, que aún estructuran nuestro mundo. Atendiendo al tema que nos ocupa, podemos decir que entonces comienzan los procesos de constitución de la subjetividad moderna que ya en el barroco, como vemos en Vico, han alcanzado su total madurez. 
En resumen, la consecuencia de todo esto es que ha habido diversos tipos de subjetividad, irreductibles unos a otros. Incluso podríamos considerar que ha habido subjetividades "inconscientes": hombres que pensaban y actuaban espontáneamente, sin un proceso reflexivo, de tal modo que apenas tenían conciencia de sí. Pero también tenemos que ha habido momentos de plenitud en el desarrollo de los ciclos. Y en este sentido los dos tipos de subjetividades, la antigua y la moderna, en su fase de completo desarrollo, habrían sido subjetividades plenas y autoconscientes.

\section{La subjetividad en fin de ciclo}

A partir del planteamiento de Vico surge un interesante problema: el paso de la subjetividad mítico-narrativa a la reflexivo-científica parece ser un tránsito cronológico, en el que lo posterior hace desaparecer totalmente a lo anterior sin que permanezca rastro de esto. De este modo, podríamos sostener que, efectivamente, a lo largo del tiempo van apareciendo diversos tipos de subjetividad, en los que se va alcanzando un mayor grado de autoconciencia, e incluso se llega un momento autodestructivo (o desconstructivo) de la propia subjetividad.

Según expone Vico al hablar del corso completo, el tránsito de la subjetividad espontánea a la crítica, parece que el paso de la sabiduría vulgar a la reflexiva y el conocido ritmo ternario de las edades de la humanidad son pasos cronológicamente sucesivos, donde los posteriores eliminan los anteriores y, en definitiva, el proceso de construcción y perfeccionamiento de la humanidad implicaría necesariamente su posterior destrucción.

Se trata, según Vico, de que la mente reflexiva, rompiendo con la sapienza poetica, se convierte en razón hipercrítica; o sea, se trata de una subjetividad crítica, que rechaza todo lo que viene de fuera, y pasa a ser una subjetividad individualista, dominada por una sensibilidad descontrolada, donde el propio capricho es un absoluto. Así describe Vico este tipo de subjetividad hipercrítica:

Los doctos ignorantes se dedican a calumniar la verdad y nacen así discursos engañosos de tal modo que de una perfecta libertad se cae en una perfecta tiranía, que es la peor de toda: la anarquía, o sea, la desenfrenada libertad de los pueblos libres (SN 1102).

Las malnacidas sutilezas de los ingenios maliciosos, con la barbarie de la reflexión, han convertido a los hombres en fieras más inhumanas de lo que antes fue la antigua barbarie. [...] A modo de bestias se han acostumbrado a no pensar más que en sus particulares utilidades, propias de cada uno, y acabando en lo último de la delicadeza o, mejor dicho, del orgullo, a modo de fieras, apenas son disgustadas, se resienten y enfurecen. Y así, en la mayor concurrencia o muchedumbre de cuerpos, vivieron como bestias inhumanas en una suma soledad de ánimos y de voluntades, no pudiendo apenas convenir dos, pues cada uno seguía el propio placer o capricho (SN 1106).

Esto sería, según Vico, lo que ha sucedido en la Antigüedad tardía y lo que sucede en nuestra posmodernidad (o mejor: Modernidad tardía), en las que la razón crítica elimina toda forma de sociedad a favor de un individualismo, que, en su extremo, se asemeja al egoísmo inicial, anterior a toda forma de sociedad. Se trata, pues, de un nuevo tipo de subjetividad caracterizada por la «barbarie de la reflexión» (SN 1106), o sea, la filosofía de la sospecha y crítica a todos los valores, y por la posverdad, es decir, cuando los «necios doctos se dedican a calumniar la verdad» (SN 1102). De este 
modo, se forja una subjetividad individualista, donde el propio punto de vista y los propios intereses se constituyen en un absoluto.

Ciertamente cualquiera puede objetar que el juicio de Vico no acierta en absoluto a diagnosticar nuestra subjetividad actual, pues no estamos en un fin de ciclo, sino en un momento de plenitud. Sin embargo, Vico podría señalar muchos signos indubitables, como él los llama, pues ya hace un siglo empezaron los discursos sobre el malestar de nuestra cultura y hoy día «la denuncia de la degradación antropológica inducida por los modelos culturales... es prácticamente unánime» (Sequeri, 2014: 10). ¿Qué pensar de la posverdad, de un relativismo que ya no se molesta en afirmar una pluralidad cacofónica de voces, sino que se sostiene que ni siquiera hay una realidad común sobre la que podamos hablar y debatir: «Ya no hay punto de vista privilegiado ni objeto común a todos los puntos de vista»? (Deleuze, 1994: 263). ¿Qué decir de una subjetividad que ha negado toda instancia externa al puro capricho subjetivo, donde no es que se niegue, sino que ni siquiera se concibe, la posibilidad de un ius naturale gentium, donde la negación de la naturaleza es "norma"? ¿Qué juicio emitir sobre una subjetividad que considera más valioso a su mascota que a su vecino, a una foca que a un nascituro, a un perro que a un posible hijo? ¿Qué pensar de la disolución de todo tipo de sociedades, incluida la familia, y la aparición de un individualismo radical donde «no pueden apenas convenir dos, pues cada uno sigue el propio placer o capricho» (SN 1106)? ¿Cómo considerar una sociedad que sólo admite la ley ciega, el puro derecho positivo establecido por la voluntad del más fuerte, por la fuerza de los votos? O dicho de otro modo, ¿qué decir de una sociedad donde su único límite es el yugo de la ley positiva, de una burocracia irracional infinita, dictada bajo la arbitrariedad de los parlamentos, que sin límites dictaminan el bien y el mal, cumpliendo así el «seréis como dioses» (Génesis 3, 5)? ¿Qué pensar de la desmesura de una subjetividad que afirma: «Sé bien que cuando el hacha de la muerte me tale se vendrá abajo el firmamento»? (Jiménez, 1918: 152).

\section{La sincronía en las modificaciones de la mente}

El juicio que Vico haría sobre nuestra sociedad y nuestra subjetividad puede parecer muy negativo, pero podríamos defendernos de él, amparándonos en que la decadencia o, si queremos, los procesos desconstructivos son necesarios, imparables. Sin embargo, Vico introduce en su visión de los procesos de lo humano un aspecto muy importante, que niega todo planteamiento determinista y abre una puerta a una alteración de los ciclos. Se trata de la sincronía de las modificaciones, que le lleva al concepto de akmé de las naciones y a un arte diagnóstica.

\section{a) Sincronía de las modificaciones}

Sin negar la procesualidad de la humanidad, de las modificaciones de la mente y de sus productos, Vico sorprendentemente afirma también la contemporaneidad de los tres estadios de la humanidad: 
Debe establecerse este principio: dado que comenzaron simultáneamente los dioses, los héroes y los hombres (puesto que eran hombres los que fantasearon los dioses y creían que su naturaleza heroica era mezcla de la de los dioses y los hombres), así al mismo tiempo comenzaron tales tres lenguas (SN 446, 412).

Hemos puesto de relieve que la diversidad de mentes no hay que entenderla como exclusiva presencia de una facultad humana, por ejemplo, del sentido o de la imaginación, sino que las modificaciones de la mente pertenecen a la mente; es decir, se trata de un predominio -no de eliminación- de una facultad sobre las otras. Así, por ejemplo, el lenguaje necesita siempre comenzar por lo sensible en su formación y, por tanto, incluso las palabras que designan conceptos puramente abstractos guardan relación con lo sensible y siempre conservan huella de su origen (SN 444). En una palabra, el hombre es sentido, fantasía y razón, y esas tres facultades están siempre presentes y operantes, de tal modo que en cada época de la humanidad se ha de producir un determinado equilibrio entre ellas, constituyendo los diversos tipos de subjetividad humana.

Ahora bien, es claro que esa simultaneidad de las facultades no contradice que la humanidad vaya pasando por diversas edades, puesto que la mente humana, en la historia de la humanidad, va procediendo desde lo sensible a lo racional, de tal modo que se da un despliegue de la razón, que consiste fundamentalmente en su plena autoposesión, superando, en la medida que le es posible, su dependencia de lo sensible: «Finalmente, habiéndose desplegado toda nuestra humana razón, alcanzó la verdad de las ideas» (SN 1045; cfr. Badaloni, 1971, 29). Por esto, Vico afirma repetidamente que «la naturaleza racional es la verdadera naturaleza humana» (SN 29), y que la tercera edad, la edad de los hombres, es la que responde al tercer tipo de naturaleza y se caracteriza por el uso de la razón ${ }^{5}$.

Así pues, Vico introduce la teleología en los procesos de humanización. No hay duda de que el hombre tiene sentidos, imaginación y razón, pero su verdadera naturaleza, lo que lo caracteriza en cuanto hombre es la racionalidad. Las diversas edades del individuo - del niño al adulto- y de la humanidad constituyen una marcha hacia la razón, hacia una razón que en sí misma se va modificando, desplegándose, hasta llegar a sí misma, a ser plenamente razón. Por tanto, toda la historia de la humanidad no es un mero sucederse fáctico de diversos estadios (mentes, edades, etc), sino un auténtico proceso teleológico, dotado de interna inteligibilidad ${ }^{6}$.

\footnotetext{
${ }^{5}$ «La terza [spezie di natura] fu natura umana, intelligente, e quindi modesta, benigna e ragionevole, la quale riconosce per leggi la coscienza, la ragione, il dovere» (SN 918). Ciertamente es necesario insistir en la importancia de la imaginación en Vico, frente a posiciones racionalistas o concepciones de la razón como algo abstracto o ahistórico, pero es preciso no perder nunca de vista que no son los sentidos ni la imaginación sino la razón la característica estrictamente humana.

${ }^{6}$ P. Piovani en su importante artículo Vico senza Hegel ha señalado la diferencia radical entre estos dos pensadores, indicando que «per Vico l'essenza è nel principio, letteralmente inteso; per Hegel è nella conclusione, in cui storia e logica s'incontrano, identificandosi. Le strade non potrebbero divergere con maggiore nettezza» (1968: 578). Piovani destaca así un aspecto de la filosofía viquiana: «Natura di cose altro non è che nascimento di esse in certi tempi e con certe guise» (SN 147); lo cual implica que la naturaleza está dada al inicio (en sentido temporal). Sin embargo, descuida la teleología viquiana por la que el Napolitano se acerca a Hegel: la verdadera naturaleza-completa, desplegada- está al final; lo propio, lo natural, en el hombre no es el vagar ferino, ni el concebir imaginativamente, sino el pleno uso de la razón, que no excluye el de los sentidos o el de la imaginación.
} 


\section{Tropelías. Revista de Teoría de la Literatura y Literatura Comparada, 31 (2019) La subjetividad contemporánea interpretada diacrónicamente a partir de G.B. Vico}

\section{b) La akmé}

Ahora bien, el estado final de razón plenamente desplegada no implica que el hombre actúe solamente según la pura razón: es razón desplegada, pero eso no tiene por qué anular las demás facultades. Esta presencia de todas las facultades y de sus actividades, aunque con predominio de la razón ya en plena posesión de sí, nos remite al concepto viquiano de akmé -estado perfecto de la humanidad-, que se expone detalladamente en el capítulo II del libro primero de la Scienza nuova prima:

Tal estado de perfección consiste en esto: fundamentarse las naciones en cierta máximas demostradas por razones constantes y practicadas con las costumbres comunes, sobre las cuales la sabiduría reflexiva de los filósofos diese la mano y sostuviese a la sabiduría vulgar de las naciones; y de este modo, coincidiesen las más reputadas academias con todos los sabios de las repúblicas (1SN 11).

Así pues, desde el punto de vista del conocimiento, la akmé se caracteriza por la unión armónica de todos los conocimientos del género humano, pero no sólo de las ciencias, sino de todo tipo de saber y actividad, incluidos los imaginativos, artísticos, técnicos, prácticos, políticos, etc.

Esto plantea el problema de cómo es posible que la sabiduría espontánea permanezca, puesto que -como vimos- se basa en la mente poética, o sea, en un tipo de subjetividad humana en la que predomina la espontaneidad creadora y que, con el correr del tiempo, ha dejado paso a la mente reflexiva, a la subjetividad científica y crítica. No se trata, en efecto, de pretender que la mente poética y sus realizaciones concretas permanezcan tal cual, sino que las distintas facultades humanas mantengan su papel y su función en el conjunto de los saberes y de las artes, todo ello dentro de la mente reflexiva, que es la nuestra, la "spiegata ragione". Esto significa que los saberes y las actividades reflexivas no eliminan las poéticas, sino que aquéllas no sólo nacen de éstas y recogen sus contenidos, sino que nunca pierden la conexión con sus orígenes: la sabiduría reflexiva hunde sus raíces en la sapienza poetica de la que nace y se alimenta. En otras palabras, la filosofía y la ciencia moderna no elimina la literatura, la lengua, la religión, el derecho, la mitología, el arte..., el saber de lo humano (SN 498).

Este concepto viquiano de akmé es decisivo para resolver el problema del papel negativo de la razón. Podría pensarse, en efecto, que la razón en cuanto tal es esencialmente negativa y, por eso, cuando alcanza su predominio en la edad de los hombres, necesariamente origina la decadencia. No es ésa la posición de Vico. Ciertamente existe la «barbarie de la reflexión» (SN 1106), pero no toda reflexión es de ese tipo, sino sólo aquélla que, rompiendo con sus orígenes poéticos, niega los contenidos de la sapienza poetica, o sea, niega el contenido de verdad que se halla en la narración mítica de nuestros orígenes y destino, de las relaciones entre nosotros mismos y con la naturaleza (SN 1102). En este sentido, es claro que el estado perfecto de la humanidad no corresponde al de los primeros inicios - el estado de naturaleza no es el más perfecto-, ni tampoco a la edad en que predomina la fantasía, sino a la edad de los hombres, en que ciertamente predomina la razón -spiegata ragione-, 
pero una razón que asume e incluye al sentido y a la fantasía ${ }^{7}$. Se trata, pues, no de una razón abstracta, desarraigada de sus orígenes, sean filogenéticos -la mente poética- sean ontogenéticos -necesitamos los sentidos y la imaginación para pensar-, sino de una subjetividad que es esencialmente reflexiva, o sea, que vuelve críticamente sobre lo previamente dado en modo acrítico, y así es reflexión, autoposesión consciente de lo dado en la sensibilidad y en la imaginación, en la tradición y en el mito, en la religión y en las leyes, en los usos y las costumbres ${ }^{8}$.

\title{
c) El arte diagnostica
}

De esta concepción teleológica de la subjetividad y, por ende, de la humanidad en cuanto tal, Vico extrae numerosas e importantes consecuencias, que contribuyen a perfilar y mostrar la importancia decisiva del concepto de akmé, hasta el punto de poder considerar este concepto como la cuarta idea rectora del pensamiento viquiano (junto con las de mente, modificación y verum factum). Entre las numerosas consecuencias, podemos subrayar las dos prácticas que de ella se derivan:

\begin{abstract}
A partir de esta ciencia, conducida con tal clase de pruebas, tenemos dos prácticas. De las cuales, una es una nueva arte crítica, que sirva de antorcha para distinguir lo verdadero en la historia oscura y fabulosa. Además de esa, la otra práctica es un arte diagnóstica, la cual, regulándonos con la sabiduría del género humano, desde los órdenes de las cosas de la humanidad, nos da los grados de su necesidad o utilidad y, en última instancia, nos da el fin principal de esta Ciencia, que es conocer los signos indubitables del estado de las naciones (1SN 391; cfr isch, 1976: 423-430; Pons, 1976: 431-448).
\end{abstract}

Ahora no nos interesa el arte crítica, que sirve para hacer historia sobre los orígenes de la humanidad, sino el arte diagnóstica, para poder juzgar sobre el estado de las naciones. Si bien Vico no pone especial énfasis en esta dimensión práctica de su Ciencia, no hay que perder de vista que toda su obra no tiene un fin puramente especulativo, pues, para el Napolitano, el conocimiento teorético se ordena al práctico, en cuanto que con éste se alcanza la perfección del ser humano.

De este modo, la nueva Ciencia viquiana nos suministra los conocimientos que permiten emitir un juicio que diagnostique el estado de una nación, según su alejamiento o acercamiento a la akmé. Por eso mismo, la Scienza nuova no sólo diagnostica, sino que también permite mostrar los caminos para alcanzar la akmé, o realcanzarla si la hemos perdido: a partir de la idea de akmé «se aprenden las prácticas de cómo la humanidad de una nación incipiente puede llegar al estado perfecto, y cómo ella,

\footnotetext{
${ }^{7}$ Modica, oponiéndose a la pretendida superioridad del estado originario, sostiene: «Ni ente più antivichiano d'una tal forma di primitivismo. Certo, per un verso, le nazioni raggiungono l'akmé non per un progressivo allontanamento dell'arché, ma, al contrario, grazie a una costante conformità delle "scienze", delle "discipline" e delle "arti" ai principî da cui erano nate, tant'è che esse decadono quando "scienze", "discipline" e "arti", anziché conformarsi a quei principî, se ne allontanano, li trascurano o addirittura li combattono» (1983: 153-170, 156-157).

${ }^{8}$ Sostiene E. Grassi que «Vico ha criticato la metafisica tradizionale che afferma la priorità del discorso razionale di fronte a quello metaforico» (1986: 122). Ciertamente Vico se opone al racionalismo abstracto, pero no hay que tomar "racional" como sinónimo de racionalismo y opuesto a metafórico. La Scienza nuova no es un discurso metafórico o imaginativo, sino estrictamente racional, cuando la razón ya ha alcanzado "il vero dell'idee". Me parece que, a veces, se ha exagerado demasiado el papel cognoscitivo de la imaginación, olvidando que nuestro conocimiento de la mente poética — clave de la Scienza nuova - no es por vía de imaginación sino de pensamiento: «Onde dicemmo sopra ch’or appena intender si può, affatto immaginar non si può, come pensassero i primi uomini che fondarono l'umanità gentilesca» (SN 378).
} 


\section{Tropelías. Revista de Teoría de la Literatura y Literatura Comparada, 31 (2019)

habiendo decaído, puede de nuevo rehacerse» ${ }^{9}$. En suma, la Scienza nuova nos proporciona las bases para poder diagnosticar el estado de las naciones y mostrar el camino que las conduzca a su perfección.

¿Y cómo se concreta todo eso? Hay que considerar que Vico reconstruyó la sapienza poetica y halló los principios de tal sabiduría, plasmados en las tres costumbres eternas que marcan el paso del vagar ferino a la sociedad humana:

Concluyamos todo lo que en general se ha visto en torno al establecimiento de los principios de esta Ciencia: que, puesto que sus principios son la providencia divina, la moderación de las pasiones con los matrimonios y la inmortalidad de las almas humanas con las sepulturas; [...] y en tales principios [...] concuerdan la sabiduría vulgar de todos los legisladores y la sabiduría reflexiva de los más reputados filósofos: esos deben ser los confines de la razón humana. Y cualquiera que desee irse fuera, vea si no se va fuera de toda la humanidad (SN 360).

Por eso, cuando se niegan esos tres principios de humanización, empieza el final del ciclo, de modo que las estructuras, instituciones, mentalidad, subjetividad y tipo de hombre construidos en un corso a partir de los esos principios viquianos comienzan a ser sistemáticamente desconstruidos: la religión mediante la secularización, la inmortalidad mediante los reductivismos e identificación del hombre con el animal, y los matrimonios mediante el individualismo y las formas caprichosas de unidades familiares.

Por el contrario, la tesis viquiana es que la razón desplegada no puede destruir tales principios, antes bien fundarlos críticamente y realizarlos, porque «lo que determina la decadencia no es, en efecto, la razón como tal, sino la hybris de la razón, o sea, la razón que se pone a «calumniar la verdad» (SN 1102) en vez de asumirla como fundamento propio» (Modica, 1983: 158). En efecto, no podemos olvidar que los principios y desarrollos de la nueva Ciencia no tienen un carácter formal, sino que están llenos de contenidos concretos, entre los que destaca el ius naturale gentium:

Así esta nueva Ciencia, o sea, la metafísica, a la luz de la providencia divina, meditando sobre la naturaleza común de las naciones, y habiendo descubierto los orígenes de las cosas divinas y humanas entre las naciones gentiles, establece un sistema de derecho natural de gentes, que procede con suma igualdad y constancia (SN 31).

En consecuencia, esos contenidos nos suministran una base suficiente para enjuiciar la marcha de nuestra sociedad, tanto desde el punto de vista de los procesos macrosociales, como de las instituciones e incluso de sus legislaciones concretas. Para concretar aún más, podemos notar que las dos sabidurías, poética y reflexiva, tienen idénticos contenidos y difieren únicamente en el modo en que poseen sus conocimientos: la sabiduría poética los posee de modo espontáneo, es más, creándolos en forma de narraciones míticas, de realizaciones espontáneas individuales y colectivas; mientras que la sapienza riposta los posee en modo reflexivo y mediato:

Cuanto primero habían sentido en torno a la sabiduría vulgar los poetas, tanto entendieron después los filósofos en torno a la sabiduría reflexiva, de modo que se puede decir que aquéllos han sido el sentido y éstos el intelecto del género humano (SN 363, 779).

\footnotetext{
9 1SN 11. Sobre esta dimensión práctica de la Scienza nuova, comenta Severino: «Questi momenti teorici [il filologico e il filosofico] alimentano la volontà di Vico di approfondire e consolidare il dominio della ragione onde evitare che "il mondo si infierisca e si rinselvi di nuovo"» (1981: 82-83).
} 


\section{Consideraciones finales}

Me parece que la teoría viquiana de las modificaciones de la mente es enormemente fecunda para la comprensión de todo lo humano y, por tanto, para la elaboración de una teoría de la subjetividad humana.

El concepto de modificación de la mente introduce, por primera vez en la historia del pensamiento, la idea de una modalización temporal intrínseca de la mente humana. De este modo, se puede establecer diversidad cronológica en las condiciones transcendentales de la subjetividad, que es fuente y origen de todo obrar humano, teórico y práctico. Esto permite establecer diversos tipos de subjetividad humana, que, a su vez, son la base para dar razón del inicio de la humanidad: mostrar las condiciones transcendentales del autohacerse del sujeto humano en su realidad individual y colectiva ${ }^{10}$. Pero, además, la teoría de las dos modificaciones de la mente - poética y reflexiva- da razón también de los procesos históricos posteriores de desarrollo o marcha hacia un tipo de subjetividad más humana, plena, capaz de unos logros más perfectos.

Al concebir Vico las modificaciones de la mente como juego unitario de facultades (sentidos, fantasía y razón), puede introducir el concepto de akmé, que le permite explicar el despliegue de la humanidad como un proceso teleológico unitario: se trata de un proceso de humanización, que va desde lo ferino a lo humano incipiente y poético, y de esto, a lo humano en sentido pleno; es decir, hacia una humanidad en la que predomine la razón. Sin embargo, es importante notar que se trata, en Vico, no de razón unilateral, sino una razón reflexiva que debe asumir, críticamente, las creaciones de la sapienza poetica, de modo que sea capaz de unir en armonía las religiones y las leyes con las ciencias y las artes, y contribuya así a la perfección de la humanidad.

Pienso que estas ideas han sido y pueden seguir siendo fecundas no sólo para la comprensión de los pueblos remotos de la antigüedad o de las sociedades primitivas, sino, muy especialmente, de nuestra actual subjetividad consciente y de nuestras sociedades, pues el papel y la naturaleza de los símbolos, de las imágenes, del cine, de la literatura, las narraciones infantiles, los mitos, las tradiciones "irracionales", etc. pueden ser mejor comprendidos a partir de las ideas viquianas: no sólo hay pensamiento abstracto, racional, científico, sino también pensamiento poético, imaginativo, fantástico, creador, que incluso tiene una función más importante en la guía y construcción de la sociedad real. Y además, ambas formas de pensamiento no se excluyen, sino que pueden y deben integrarse en un tipo de sujeto humano que cultive todos esos aspectos en una unidad teleológica superior, que dé lugar a la akmé individual y social, bajo la guía de la spiegata ragione.

Además, a partir de las ideas viquianas podemos comprender que, a lo largo de la historia o, al menos, en el esplendor el mundo antiguo, hubo formas de conciencia tan plenas, autónomas y

\footnotetext{
${ }^{10}$ «L'uomo ignorante si fa regola dell'universo, siccome negli esempli arrecati egli di se stesso ha fatto un intiero mondo. Perché come la metafisica ragionata insegna che homo intelligendo fit omnia, così questa metafisica fantasticata dimostra che homo non intelligendo fit omnia; e forse con più di verità detto questo che quello, perché l'uomo con l'intendere spiega la sua mente e comprende esse cose, ma col non intendere egli di sé fa esse cose e, col transformandovisi, lo diventa» (SN 405).
} 
autoconscientes como la nuestra. $\mathrm{Y}$ al mismo tiempo, podemos reconocer en nuestro actual individualismo, subjetivismo, relativismo o incluso absolutización de nuestra subjetividad, una forma distorsionada de subjetividad que ya se dio en la Antigüedad tardía y que no constituye un logro, sino más bien la disolución del sujeto. Esta desconstrucción no es un destino necesario, sino que habrá de ser superada en el tercer corso de nuestra Europa, que, con las ideas de Vico, podrá estar lleno de esplendor, pues a partir de la akmé podremos saber qué tipo de subjetividad y de sociedad hay que construir, pues «podemos aprender los procedimientos para que la humanidad de una nación incipiente pueda llegar al estado perfecto, y cómo ella, habiendo decaído, puede de nuevo alcanzar su plenitud» (1SN 11).

\section{Bibliografía}

Agustín de Hipona: Contra academicos, en Patrologia latina, J.-P. Migne, ed., vol. XXXII, pp. 906958, París, 1845.

ARISTÓTELES: Ethica nicomachea, en Opera, ex recensione Inmanuelis Bekkeri, Berlín, Academia Regia Borussica, 1960.

BADALONI, N. (1971): «Introduzione», en Vico, Giambattista, Opere filosofiche, a cura di Paolo Cristofolini, Firenze, Sansoni.

Calvo, P. (2016): «The philosophy of plant neurobiology: a manifesto», Synthese, 193, pp. 13231343.

CICERÓN: De re publica: librorum sex quae manserunt, Barcelona, Bosch, 1980.

Deleuze, G. (1994): La lógica del sentido. Barcelona, Paidós.

Fisch, M.H. (1976): «Vicos's Practica», en G. Tagliacozzo - D.Ph. Verene, eds., G.B. Vico's Science of humanity, Baltimore, J. Hopkins Univ. Press, pp. 423-430.

GARCÍA MARQUÉS, A. (1995): Vico. Unidad y principio del saber. Valencia, Nau llibres. (2016-2017): «El verum factum en la génesis de las obras de Vico», Cuadernos sobre Vico 30-31, pp. 143-162.

GÉNESIS: en Biblia sacra, iuxta vulgatam clementinam, Alberto Colunga y Lorenzo Turrado eds., BAC, Madrid 1977.

Grassi, E. (1968), «G.B. Vico filosofo "epocal”», en Varios, G.B. Vico: Poesia, logica religione, Brescia, Morcelliana, pp. 103-123.

JACOBELli, A.M. (1968): «Il mito nel pensiero di Vico», en Varios, Omaggio a Vico. Napoli, Morano, pp. 37-72.

JiméneZ, J.R. (1918): Eternidades, 1916-17, en Obras de Juan Ramón Jiménez, Madrid, Tip. Lit. A. de Ángel Alcoy (S. en C.).

ModicA, G. (1983): La filosofia del "senso comune” in Giambattista Vico. Caltanissetta-Roma, Sciascia.

Отто, S. (1977): «Interprétation transcendantale de l'axiome "verum et factum convertuntur"», en Archives de Philosophie, XL, pp. 13-39. 
Piovani, P. (1968): «Vico senza Hegel», Omaggio a Vico, Napoli, Morano, pp. 551-586.

Pons, A. (1976): «Prudence and Providence: the "Pratica della Scienza nuova" and the problem of theory and practice in Vico», en G. Tagliacozzo - D.Ph. Verene (ed.), G.B. Vico's Science of humanity, Baltimore, J. Hopkins Univ. Press, pp. 431-448.

SEQUERI, P. (2014): Contra los ídolos posmodernos. Barcelona, Herder.

SEverino, G. (1981): Principi e modificazioni della mente in Vico. Genova, Il Melangolo.

VICO, G.B. (1725): Princìi di una Scienza nuova intorno alla natura delle nazioni por la cuale si ritruovano i principi di altro sistema del diritto naturale delle genti, en Opere filosofiche, Paolo Cristofolini, ed., Firenze, Sansoni, 1971. Utilizo la abreviatua canónica 1SN y el paragrafeado de la ed. Nicolini.

(1744): Principi di Scienza nuova d'intorno alla natura comune delle nazioni, en Opere filosofiche, Paolo Cristofolini, ed., Firenze, Sansoni, 1971. Utilizo la abreviatua canónica SN y el paragrafeado de la ed. Nicolini.

ZúNICA, I. (1998): Conocimiento y sociedad. Alicante. Interlibro. 